\title{
Semantic neighborhood effects on the recognition of ambiguous words
}

\author{
LAWRENCE LOCKER, JR., GREG B. SIMPSON, and MARK YATES \\ University of Kansas, Lawrence, Kansas
}

\begin{abstract}
The effect of semantic neighborhood on the processing of ambiguous words was examined in two lexical decision experiments. Semantic neighborhood was defined in terms of semantic set size and network connectivity. In Experiment 1, the variables of semantic set size, network connectivity, and ambiguity were crossed. An ambiguity advantage was observed only within small-set low-connectivity words. In Experiment 2, the effect of network connectivity on the processing of words of high and low meaning relatedness was examined. Participants responded more rapidly to words of high meaning relatedness, relative to words of low meaning relatedness, but only within high-connectivity words. These results are interpreted within a framework in which both semantic feedback processes and meaninglevel competition can affect the recognition of semantically ambiguous words.
\end{abstract}

The role of semantics in word recognition has received much attention in recent years (e.g., Azuma \& Van Orden, 1997; Buchanan, Westbury, \& Burgess, 2001; Pexman \& Lupker, 1999; Pexman, Lupker, \& Hino, 2002; Strain, Patterson, \& Seidenberg, 1995; Yates, Locker, \& Simpson, 2001). A common finding is that the more enriched the semantic representation associated with a given word, the more rapidly that word is processed. One account of the effect of word meaning has been in terms of semantic feedback models (Balota, Ferraro, \& Connor, 1991; Hino \& Lupker, 1996; Pexman \& Lupker, 1999; Pexman et al., 2002; Yates et al., 2001). That is, within an architecture that includes fully interconnected units representing orthography, phonology, and semantics, settling of activation at the orthographic or phonological level can be facilitated via top-down activation from semantics. In lexical decision, for example, it is assumed that the decision process is based primarily on settling of activation at the orthographic level (Pexman \& Lupker, 1999). Feedback strength from semantics to orthography is enhanced for words with a rich semantic representation, relative to words with a less enriched representation. Therefore, processing at the orthographic level is facilitated for words that are better represented at the level of meaning. A similar effect of meaning in word naming has been attributed to a facilitative effect of semantics on phonological processing (Pexman et al., 2002).

Support for the early influence of semantics in word recognition has been provided by studies in which the effects of variables that were assumed to be reflective of

\footnotetext{
The authors thank George Kellas and Kimberly Metcalf for providing us with meaning relatedness norms. The authors also thank George Kellas, Ruth Ann Atchley, Jay Rueckl, Penny Pexman, Lori Buchanan, and Steve Joordens for their helpful comments on earlier drafts of this paper. Correspondence should be addressed to L. Locker, Jr., 1415 Jayhawk Blvd., 426 Fraser, Lawrence, KS 66044 (e-mail: 1lockerj@ ku.edu).
}

meaning-level activation were investigated (e.g., Pexman et al., 2002; Strain et al., 1995; Yates et al., 2001). For example, findings reported by Pexman et al. revealed a processing advantage for words for which participants could generate a large of number of semantic features. That is, both lexical decision and naming latencies were shorter for words associated with a greater number of semantic features, relative to words for which participants could generate relatively few features. Similarly, studies in which the effect of semantic set size in lexical decision has been investigated (i.e., the number of associates related to a given word; Nelson, McEvoy, \& Schreiber, 1999) have shown that words associated with a larger semantic set are recognized more rapidly than words associated with a smaller set (Buchanan et al., 2001; Yates et al., 2001). The effect of both number of features and semantic set size has been accounted for in terms of an advantage in feedback semantics (e.g., Pexman et al., 2002; Yates et al., 2001).

However, any account of the role of meaning in word recognition must also be able to deal effectively with the issue of semantic ambiguity (i.e., words associated with multiple meanings, such as bank, or multiple senses of meanings, such as field). Previous studies have indicated that, generally, ambiguous words are recognized more rapidly in standard word recognition tasks than are nonambiguous words (Hino \& Lupker, 1996; Jastrzembski, 1981; Kellas, Ferraro, \& Simpson, 1988; Millis \& Button, 1989; Pexman \& Lupker, 1999). However, ambiguity presents a special problem because, whereas the facilitative effect of ambiguity has been observed in a number of studies (e.g., Hino \& Lupker, 1996; Kellas et al., 1988; Millis \& Button, 1989; Pexman \& Lupker, 1999), some researchers either have been unable to replicate this effect successfully (e.g., Azuma \& Van Orden, 1997; Forster \& Bednall, 1976; Gernsbacher, 1984) or have found an ambiguity disadvantage (Rodd, Gaskell, \& Marslen-Wilson, 2002). 
Pexman and Lupker (1999) argued that the ambiguity advantage in lexical decision is consistent with predictions from a semantic feedback framework. That is, ambiguous words are assumed to be multiply represented at the level of meaning. Feedback strength should, therefore, be stronger for words associated with multiple meanings, as opposed to words with a single meaning. In order to assess the feedback hypothesis, Pexman and Lupker performed two lexical decision experiments in which they investigated the effects of semantic ambiguity, homophony (i.e., words of different spelling that share the same phonological code, such as made and maid) and nonword foil type (i.e., pronounceable pseudowords vs. pseudohomophones). Pexman and Lupker argued that the effect of homophony (i.e., slower response times to homophones than to nonhomophones) is also consistent with the predictions from a feedback model. That is, the common phonological code of a homophonic word feeds back activation to its different spellings (i.e., orthographic codes). The activation of disparate orthographic codes creates competition within this level, slowing processing. Pexman and Lupker predicted that, if the mechanism of feedback can account for the effects of both ambiguity and homophony, these effects should cooccur in a lexical decision task. Furthermore, Pexman and Lupker predicted that these effects should be of a greater magnitude in the presence of pseudohomophonesthan in the presence of pronounceable pseudowords. The presence of pseudohomophones is assumed to make lexical decisions more difficult, prompting a greater reliance on semantic-level information (Pexman \& Lupker, 1999; Van Orden \& Goldinger, 1994). The results of two lexical decision experiments supported their predictions. However, although these results provide support for a feedback account of the multiple-meaning advantage in lexical decision, this study also suggests that the activation of multiple representations (i.e., orthographic) can slow lexical decision responses. This possibility has been confirmed by studies in which the effects of synonymy have been assessed (Hino, Lupker, \& Pexman, 2002; Pecher, 2001). Hino et al., for example, showed a processing disadvantage for words that have a familiar synonym. Hino et al. attributed this finding to orthographic-level competition. That is, the common meaning representation shared by a word and its synonym feeds back activation to their respective spellings, which, similar to the homophone effect, slows processing, owing to orthographiclevel competition.

Although these studies provide evidence that feedback processes, as well as orthographic competition, can affect lexical decision, relatively little research has investigated the potential for meaning-level competition effects in lexical decision. This issue is of importance, however, because some researchers have noted that the prediction concerning the processing of ambiguous words in many parallel distributed processing (PDP) models is a disadvantage in processing. That is, the instantiation of multiple meaning patterns across a single set of nodes should result in competition that slows response times (e.g., Azuma \& Van Orden, 1997; Joordens \& Besner, 1994; Rodd et al., 2002).

A possibility explored by Azuma and Van Orden (1997) is that semantic-level competition may be overcome if the multiple meanings associated with a word are related. That is, for words whose meanings correspond to separate attractors (i.e., stable states), competition should slow processing as the system moves toward one of the meaning patterns. However, words whose meanings are related (i.e., share semantic features) may move toward the same broad basin of attraction, so that interference between the meanings is relatively minimal (e.g., Kawamoto, 1993; Rodd et al., 2002). Therefore, Azuma and Van Orden predicted that if competition does arise in the processing of multiple meanings, words whose meanings are related should exhibit a processing advantage, relative to words with unrelated meanings. To assess this hypothesis, Azuma and Van Orden examined the effects of both number of meanings and relatedness of meanings in two lexical decision experiments. In the first experiment, they investigated the effect of these variables relative to nonword foil type (i.e., pronounceable pseudowords vs. pseudohomophones). In the pseudohomophone condition, there were effects of both number of meanings and relatedness of meanings, as well as an interaction such that the meaning relatedness effect (i.e., faster response times for words with highly related meanings) was observed only for words with few meanings. A subsequent experiment replicated the effect of meaning relatedness for words with few meanings, but did not replicate the number-of-meanings effect (Azuma \& Van Orden, 1997).

Although Azuma and Van Orden (1997) provided some evidence that competition effects may result from the activation of multiple meanings (see also Rodd et al., 2002), the majority of studies have shown that words with multiple meanings are typically recognized faster than words associated with a single meaning (e.g., Kellas et al., 1988; Millis \& Button, 1989; Rubenstein, Garfield, \& Millikan, 1970). However, given the inconsistencies concerning the facilitative effect of ambiguity (e.g., Azuma \& Van Orden, 1997; Forster \& Bednall, 1976; Rodd et al., 2002) and the contrary predictions made by differing models (e.g., Azuma \& Van Orden, 1997; Forster \& Bednall, 1976; Joordens \& Besner, 1994; Pexman \& Lupker, 1999), this issue should be explored further.

\section{EXPERIMENT 1}

One possible explanation for the inconsistent findings concerning the facilitative effect of ambiguity is that, in some cases, this facilitative effect is diminished by competition effects at the semantic level. Atchley, Burgess, and Keeney (1999), for example, suggested that the online processing of multiple meanings composed of unrelated features may require the inhibition of features related to one meaning. If this is the case, competition 
effects should increase as the scope or magnitude of activation of the disparate meanings increases. Furthermore, if semantic competition does arise, this interference should be inversely related to any facilitative effect due to feedback. That is, strong competition effects at the level of meaning may diminish the advantage for ambiguous words by reducing the strength of semantic feedback or by causing this feedback activation to be inconsistent (e.g., Kawamoto, Farrar, \& Kello, 1994). In either case, the facilitative influence of multiple meanings would be substantially diminished. In the present study, we explored the possibility that semantic neighborhood metrics provide a measure of the strength or scope of the activation of the meanings associated with an ambiguous word. As measures of semantic neighborhood, we utilized semantic set size and network connectivity (Nelson et al., 1999). A word's semantic set size is determined by presenting participants a list of words and asking them to provide a single response that is meaningfully related (Schreiber \& Carter, in press). The number of responses across participants composes the word's set. The network connectivity of a word's semantic set is determined by norming each word of the set to determine its associates, since in many cases, words in a given semantic set will also be related to each other (Nelson, Bennett, Gee, \& Schreiber, 1993). To illustrate these variables in more detail, consider the example of the word $d o g$. The set size of $d o g$ is composed of cat, animal, puppy, friend, and house. Thus, $d o g$ has a neighborhood size of five. However, there are two associative connections among the elements of the set of $d o g$ (i.e., the word animal is related to both cat and house). These two relations constitute the word's connectivity (i.e., the connectivity measure for the word $\operatorname{dog}$ is .40 , which is derived by dividing the number of associative connections within the neighborhood by the total neighborhood size; Nelson et al., 1993). By the criterion described below, a word such as $d o g$ would be considered to have a small set size and low connectivity. Words vary substantially, however, both in their degree of connectivity and in semantic set size. In regards to semantic ambiguity, the relationship between the variables of set size and connectivity is the same for ambiguous and nonambiguous words. However, in the case of an ambiguous word, the associates that compose the neighborhood are reflective of its disparate meanings ${ }^{1}$ (e.g., Gee, 1997).

It should also be noted that the use of set size and network connectivity as measures of meaning-level activation assumes that the responses provided by participants that compose a word's semantic neighborhood reflect semantic relationships. This viewpoint should be qualified, however, because of the current debate concerning what constitutes semantic relationships. One view, for example, holds that words such as dog-cat are semantically related (e.g., Joordens \& Becker, 1997), whereas words such as dog-house are not. The distinction between the two relationships of the word $d o g$ described above could be considered congruent with a categorical, or object-based, view of semantics (e.g., Buchanan et al., 2001; Lucas, 2000). This view holds that words are semantically related if they significantly overlap in terms of their physical properties. An alternative viewpoint, however, is that words are meaningfully related if they are somehow associated or share similar contexts (i.e., a language-based view; e.g., Buchanan et al., 2001; Masson, 1995). In terms of this viewpoint, dog-house would be considered semantically related on the basis of an individual's experience with these concepts in similar contexts. The purpose of the present paper is not to provide a resolution to this debate. It is likely, as Buchanan et al. noted, that both types of knowledge (i.e., object- vs. languagebased) play an important role in the semantic system. Semantic neighborhoods undoubtedly contain both types of relationships, although the precise nature of these relationships is not specified. We assume, however, that the participants did exploit their conceptual knowledge when they produced responses that composed semantic neighborhoods. Therefore, we utilized these metrics as coarse-grained measures of the relative scope of conceptual knowledge, without assuming that they are necessarily definitive in terms of describing the attributes of one's conceptual knowledge (see McRae, De Sa, \& Seidenberg, 1997, for a similar view concerning participant-generated semantic features).

As was described above, we hypothesize that the processing of ambiguous words may be a function of both facilitation and competition effects. Facilitation is assumed to arise from the processing of multiple meanings in terms of enhanced semantic feedback activation to orthography. However, the processing of multiple meanings may also create interference from competition within the semantic level. Therefore, it is possible that, in some conditions, within-level interference from competition could be sufficiently robust to counter between-level facilitative effects (e.g., weaken feedback strength). Since prior research has suggested that the degree of competition may be a function of how multiple meanings are represented in memory (e.g., Azuma \& Van Orden, 1997; Rodd et al., 2002), we propose that one factor that may contribute to semantic competition is the scope of activation of the meanings associated with an ambiguous word (e.g., Atchley et al., 1999). That is, meanings that are richly represented in memory are more strongly activated and may interfere with each other more so than do meanings that are weakly activated. If this is the case, an ambiguity advantage would be most likely to be observed for words for which meaning-level activation is relatively weak. Therefore, in terms of semantic neighborhood, we predicted that an ambiguity advantage would be observed primarily for words that are relatively small in set size and low in connectivity and are, therefore, relatively weak in semantic activation. Alternatively, in a system in which the effect of ambiguity is due entirely to feedback strength (Pexman \& Lupker, 1999), no advantage of semantic ambiguity may be observed when ambiguous and nonambiguous words are equated in terms of semantic activation (i.e., word 
types are equated in terms of the magnitude of set size and connectivity and, therefore, should be approximately equivalent in terms of feedback strength). Experiment 1 was conducted to investigate these possibilities.

\section{Method}

Participants. The participants were 64 undergraduate psychology students at the University of Kansas, who participated in the study for course credit. The data from 3 participants were excluded from the experiment on the basis of excessive error rates $(>15 \%)$. Therefore, the analyses reported are based on the data from 61 participants. All the participants had normal or corrected-to-normal vision and were native English speakers.

Stimuli. The stimuli consisted of an 80 -word list formed by crossing the three variables of semantic ambiguity (ambiguous or nonambiguous), semantic set size (large or small), and network connectivity (high or low). All the stimuli were selected from the University of South Florida Word Association, Rhyme, and Word Fragment Norms (Nelson et al., 1999). Ambiguous words in that database were selected from previous studies or normative data (e.g., Nelson, McEvoy, Walling, \& Wheeler, 1980; Twilley, Dixon, Taylor, \& Clark, 1994; see Nelson et al., 1999, for a complete listing of homograph sources). Words with a number of associates greater than 16 were classif ied as large set $(M=20.35, S D=3.02)$. Words with associates numbering 10 or fewer were classified as small set $(M=6.88, S D=1.83)$. High-connectivity words ranged from 1.8 connections or greater $(M=2.41, S D=0.47)$. Lowconnectivity words ranged from 1.2 connections or fewer $(M=0.68$, $S D=0.21)$. All word types were equated in terms of length, printed frequency (Kučera \& Francis, 1967), orthographic neighborhood, concreteness (Nelson et al., 1999), and positional bigram frequency (Massaro, Taylor, Venezky, Jastrzembski, \& Lucas, 1980). The stimuli are shown in Appendix A. Eighty orthographically legal pseudowords, which were equated with the target stimuli in terms of positional bigram frequency (Massaro et al., 1980), were selected as fillers, for a total of 160 experimental trials. An additional 10 words and 10 pseudowords that did not appear in the experimental trials were presented as practice trials for each participant.

Procedure. Stimulus presentation and recording of response latencies and accuracy were controlled by an IBM-compatible PC, utilizing Micro Experimental Laboratory (MEL) Version 2.0 (Schneider, 1988). At the beginning of each trial, a fixation stimulus (+) appeared in the middle of the screen for $750 \mathrm{msec}$. The fixation was then removed, and a word or nonword was presented in lowercase letters. The target remained on the screen until the participant responded. Lexical decisions were made by pressing the $l$ and the $a$ keys. Response hand was counterbalanced such that half of the participants responded word with their dominant hand, and half responded with their nondominant hand. Presentation of trials was randomized for each participant.

\section{Results and Discussion}

Mean lexical decision latencies and error proportions for both participants and items were submitted to a 2 (semantic ambiguity: ambiguous vs. nonambiguous $) \times 2$ (semantic set size: large vs. small) $\times 2$ (network connectivity: high vs. low) within-subjects factorial analysis of variance (ANOVA) for participants and a betweenword ANOVA for items. ${ }^{2}$ Outliers were defined as latencies shorter than $250 \mathrm{msec}$ and longer than $2,000 \mathrm{msec}$. This criterion resulted in the exclusion of fewer than $1 \%$ of the data points from the analyses. Mean response latencies and error percentages for each word condition are reported in Table 1.

Analyses of the response latencies revealed an advantage for words with large semantic sets $\left[F_{1}(1,60)=\right.$ $\left.54.77, p<.001 ; F_{2}(1,72)=9.22, p<.01\right]$, as well as a marginal advantage for ambiguous words $\left[F_{1}(1,60)=\right.$ $\left.3.30, p<.08 ; F_{2}<1\right]$. However, these effects were qualified by a three-way interaction of semantic ambiguity, semantic set size, and network connectivity $\left[F_{1}(1,60)=\right.$ $\left.10.24, p<.01 ; F_{2}<1\right]$. This interaction was analyzed by examining the effects of ambiguity and connectivity separately for small- and large-set words. For small-set words, the interaction of ambiguity and connectivity was significant by participants $\left[F_{1}(1,60)=6.76, p<.05\right]$, but not by items $\left(F_{2}<1\right)$. Simple-effect analyses revealed that, among low-connectivity words, ambiguous words were recognized more rapidly than nonambiguous words $\left[F_{1}(1,60)=9.83, p<.01 ; F_{2}<1\right]$. For high-connectivity words, however, there was no effect of ambiguity (both $F$ s $<1)$. Large-set words also showed an interaction of ambiguity and connectivity $\left[F_{1}(1,60)=4.26, p<.05\right.$; $\left.F_{2}<1\right]$. However, simple-effect analyses revealed that the effect of ambiguity was not significant within lowconnectivity $\left[F_{1}(1,60)=1.39, p>.05 ; F_{2}<1\right]$ or highconnectivity $\left[F_{1}(1,60)=2.51, p>.05 ; F_{2}<1\right]$ words.

The analyses of error percentages revealed an interaction involving semantic ambiguity and semantic set size $\left[F_{1}(1,60)=31.11, p<.001 ; F_{2}(1,72)=1.60, p>\right.$ .05]. Simple-effect analyses revealed that ambiguous words were responded to more accurately than nonambiguous words within small-set words $\left[F_{1}(1,60)=\right.$ $\left.30.17, p<.001 ; F_{2}(1,38)=1.32, p>.05\right]$, but not within large-set words $\left[F_{1}(1,60)=2.46, p>.05 ; F_{2}<1\right]$.

Table 1

Lexical Decision Latencies (in Milliseconds), Standard Deviations, and Error Percentages Within Large-Set and Small-Set Words for the Stimuli From Experiment 1

\begin{tabular}{llllllll}
\hline & \multicolumn{3}{c}{ High Connectivity } & & \multicolumn{3}{c}{ Low Connectivity } \\
Semantic Set & RT & $S D$ & \% Error & & RT & $S D$ & \% Error \\
\hline Large & & & & & & & \\
$\quad$ Ambiguous & 576 & 74.3 & 4 & & 585 & 69.9 & 4 \\
$\quad$ Nonambiguous & 587 & 66.7 & 2 & & 577 & 68.7 & 4 \\
Small & & & & & & \\
$\quad$ Ambiguous & 611 & 88.3 & 7 & & 604 & 72.5 & 6 \\
$\quad$ Nonambiguous & 609 & 70.3 & 10 & & 627 & 75.2 & 12 \\
\hline
\end{tabular}


The results from Experiment 1 provide some support for a model of the processing of meaning that includes facilitation as well as competition effects. Evidence in favor of the facilitative effect of word meaning is provided by the results concerning semantic set size. Replicating previous findings, words with a large set were recognized more rapidly and accurately than words with a small set (e.g., Buchanan et al., 2001; Yates et al., 2001).

Most notable, however, was the pattern of results concerning the effect of ambiguity. We predicted that the facilitative effect of ambiguity may be a function of the extent to which interference from competition arises at the semantic level. Furthermore, we hypothesized that competition effects should be greater when meanings are more strongly activated or better represented at the meaning level. This prediction was confirmed in that a reliable advantage for ambiguous words was observed only within small-set low-connectivity words in the latency data and only within small-set words in the accuracy data.

Although the results of Experiment 1 were congruent with the predictions, a second experiment was conducted to ensure that the pattern of effects described above could, in fact, be attributed to competition. Therefore, the purpose of Experiment 2 was to provide converging evidence for the existence of meaning-level competition effects through a manipulation of meaning relatedness.

\section{EXPERIMENT 2}

As was described above, words with related meanings are assumed to be processed more efficiently than words with unrelated meanings, since words with related meanings are presumably less affected by interference from competition (Azuma \& Van Orden, 1997). However, given the results from Experiment 1, the processing advantage for words with related meanings may also be a function of the scope of semantic activation. That is, if the scope of semantic activation is related to the magnitude of competition, words with related meanings should exhibit a greater advantage when interference from competition is more robust (i.e., enhanced semantic activation) than when competition is relatively weak. In Experiment 2 , we assessed this hypothesis by manipulating competition effects for ambiguous words with high and low meaning relatedness. Because of the restrictions placed on the stimuli (e.g., availability of meaning relatedness ratings; control variables, such as orthographic neighborhood, bigram frequency, etc.), it was not possible to cross meaning relatedness, semantic set size, and network connectivity fully. Therefore, semantic set size was held constant, and network connectivity was manipulated in the present experiment. If the degree of network connectivity does contribute to enhanced competition effects, as the results of Experiment 1 suggest, a more robust advantage for meaning relatedness should be observed for high- than for low-connectivity words.

\section{Method}

Participants. The participants were 51 undergraduate psychology students at the University of Kansas who participated in the experiment for course credit. The data from 1 participant were excluded from the analyses on the basis of an excessive error rate $(>15 \%)$. Therefore, the analyses reported are based on the data from 50 participants. All the participants had normal or corrected-to-normal vision and were native English speakers.

Stimuli. A list of 40 homographs was constructed by crossing the variables of meaning relatedness (high or low) and network connectivity (high or low). The stimuli were selected from a corpus of words that had been normed for relatedness of meaning (Metcalf, Kellas, \& Vu, 1999). Norming participants were asked to rate, on a scale of 1 (unrelated) to 9 (very related), the relatedness of the two meanings provided for each homograph. Only words with four or fewer meanings were used, since this measure may not be valid for words with many meanings (see Azuma \& Van Orden, 1997). The mean relatedness scores were $5.35(S D=1.24)$ and $1.78(S D=0.33)$ for words with high and low meaning relatedness, respectively. The number of connections for high- and low-connectivity words, respectively, was $1.93(S D=0.28)$ and $0.82(S D=0.19)$. The words are shown in Appendix B. Forty pseudohomophones were selected to serve as nonword fillers in the lexical decision task. Pseudohomophone foils were utilized in this experiment, because the meaning relatedness effect was observed by Azuma and Van Orden only in the presence of pseudohomophone foils (see also Rodd et al., 2002). All the stimulus conditions were equated in terms of semantic set size, concreteness (Nelson et al., 1999), orthographic neighborhood, word frequency (Kučera \& Francis, 1967), and positional bigram frequency (Massaro et al., 1980). In addition, the base words of the pseudohomophones were equated with the target words in terms of semantic set size, network connectivity, concreteness (Nelson et al., 1999), orthographic neighborhood, word frequency (Kučera \& Francis, 1967), and positional bigram frequency (Massaro et al., 1980). Fifteen words and 15 pseudohomophones that did not appear in the experimental trials were selected as practice stimuli. Thus, there were 30 practice trials and $80 \mathrm{ex}-$ perimental trials.

Procedure. The experimental procedure was the same as that in Experiment 1, with the exception that the participants were advised that some letter strings would be presented that did not form real words but sounded like real words. The participants were instructed to respond word to a letter string only if it formed a real word, regardless of how it would be pronounced.

\section{Results and Discussion}

Lexical decision latencies and error proportions were submitted to a 2 (meaning relatedness: high vs. low) $\times$ 2 (network connectivity:high vs. low) within-subjectsfactorial ANOVA for participants and a between-word factorial ANOVA for items. Response latencies shorter than $250 \mathrm{msec}$ or longer than $2,000 \mathrm{msec}$ were defined as outliers and were excluded from the analyses. This resulted

\section{Table 2}

Lexical Decision Latencies (in Milliseconds), Standard Deviations, and Error Percentages for the Stimuli From Experiment 2

\begin{tabular}{cccccccc}
\hline & \multicolumn{3}{c}{ High Connectivity } & & \multicolumn{3}{c}{ Low Connectivity } \\
\cline { 2 - 4 } \cline { 7 - 8 } Relatedness & RT & \multicolumn{1}{c}{$S D$} & \% Error & & RT & $S D$ & \% Error \\
\hline High & 562 & 71.8 & 2 & & 595 & 87.1 & 6 \\
Low & 611 & 108.2 & 10 & & 582 & 83.5 & 4 \\
\hline
\end{tabular}


in the exclusion of fewer than $1 \%$ of the data points. Mean response latencies and error percentages for each word condition are listed in Table 2.

The analysis of response latencies revealed an effect of meaning relatedness $\left[F_{1}(1,49)=6.84, p<.05 ; F_{2}<1\right]$, reflecting the finding that words rated higher in meaning relatedness were responded to more rapidly than words of lower meaning relatedness. However, these results were qualified by an interaction between meaning relatedness and network connectivity $\left[F_{1}(1,49)=21.38, p<.001\right.$; $\left.F_{2}(1,36)=3.20, p<.10\right]$. Simple-effect analyses of meaning relatedness revealed that words with highly related meanings were responded to more rapidly than words of low meaning relatedness within high-connectivity words $\left[F_{1}(1,49)=20.03, p<.001 ; F_{2}(1,18)=7.59, p<.05\right]$, but not within low-connectivity words $\left[F_{1}(1,49)=2.44\right.$, $\left.p>.05 ; F_{2}<1\right]$.

The pattern of results in the accuracy data also revealed an interaction between meaning relatedness and network connectivity $\left[F_{1}(1,49)=23.17, p<.001 ; F_{2}(1,36)=9.24\right.$, $p<.01]$. Simple-effect analyses revealed that the participants responded more accurately to words with highly related meanings within high-connectivitywords $\left[F_{1}(1,49)=\right.$ $\left.30.86, p<.001 ; F_{2}(1,18)=15.91, p<.01\right]$, but not within low-connectivity words $\left[F_{1}(1,49)=3.0, p>.05 ; F_{2}<1\right]$.

A robust effect of meaning relatedness was observed for words in which the scope of semantic activation was of a greater magnitude (i.e., high connectivity). However, no reliable effect of meaning relatedness was observed within low-connectivity words. As with the findings from Experiment 1, these results can be accounted for within a framework in which the processing of multiple meanings is affected by competition (Azuma \& Van Orden, 1997; Rodd et al., 2002) that is partially a function of the strength of semantic activation (i.e., as semantic activation of meanings increases, competition strength increases).

Within the framework described here, words whose meanings are related should be less affected by competition (i.e., slowed in terms of processing) than are words whose meanings are unrelated. If competition effects are related to the magnitude of semantic activation, responses to words of low meaning relatedness should be slowed when semantic activation is enhanced (i.e., competition effects are more robust). However, in conditions in which semantic activation is weaker (i.e., low connectivity), the processing of words of low meaning relatedness should not be slowed substantially. The results from Experiment 2 support this contention and provide further evidence for the relationship between the scope of semantic activation and competition effects in the processing of ambiguous words.

\section{GENERAL DISCUSSION}

The results of the experiments reported here demonstrate that characteristics of semantic neighborhood can affect the processing of ambiguous words. That is, the ef- fects both of multiple meanings (i.e., shorter response times for ambiguous words) and of relatedness of meanings (i.e., shorter response times for words with related meanings) appear to be partially a function of the scope of semantic activation, as indexed by semantic set size and network connectivity. We have argued that these results can be accounted for in terms of a semantic feedback model of word recognition (e.g., Pexman \& Lupker, 1999; Pexman et al., 2002; Yates et al., 2001). However, we have extended this model to include the potential for meaning-level competition effects (e.g., Azuma \& Van Orden, 1997; Joordens \& Besner, 1994; Rodd et al., 2002). The possibility of competition is suggested by the apparent inconsistencies observed in studies concerning the facilitative effect of ambiguity in lexical decision, as well the evidence from studies of the effect of this variable in such tasks as semantic priming and text comprehension (e.g., Rayner \& Duffy, 1986; Simpson \& Adamopoulos, 2001; Simpson \& Burgess, 1985).

In the present study, we propose that one possible explanation for the inconsistency of the facilitative effect of ambiguity in lexical decision is that competition does influence processing of words presented in isolation. However, the magnitude or degree to which competition affects processing is a function of the nature of the meaning representation (e.g., Azuma \& Van Orden, 1997; Rodd et al., 2002). Some support for this hypothesis was provided by the results of Experiment 1, in that an ambiguity advantage was observed only within small-set low-connectivity words. To account for these results, we proposed that multiple meanings that are better represented at the meaning level may compete to a greater degree than do meanings that are relatively weak in terms of semantic activation (e.g., Atchley et al., 1999). To provide converging evidence that the pattern of results in Experiment 1 could be attributable to competition, Experiment 2 was conducted to examine the effects of meaning relatedness relative to the magnitude of semantic activation. As was described above, words with related meanings are assumed to be processed more efficiently, since they are less affected by competition (e.g., Azuma \& Van Orden, 1997). If semantic neighborhood activation influences the degree of competition, as the results from Experiment 1 suggest, an advantage for words with related meanings would be predicted to be observed primarily in conditions in which semantic activation is more robust. This prediction was supported by the results observed in Experiment 2, in that an effect of meaning relatedness was observed only within highconnectivity words. Thus, the results of the two experiments reported here do appear to support a framework in which the processing of multiple-meaning words is affected by semantic competition.

The notion that competition may influence the processing of multiple meanings is consistent with predictions from distributed models of semantic processing (e.g., Joordens \& Besner, 1994; Kawamoto et al., 1994; Piercey \& Joordens, 2000). Particularly relevant to the 
facilitation/competition framework discussed in the present paper is a two-stage process model proposed by Piercey and Joordens to account for the finding that words with multiple meanings are processed more efficiently than unambiguous words in such tasks as lexical decision, but less efficiently in such tasks as reading of connected text (e.g., Rayner \& Duffy, 1986). This model was based on findings from simulations conducted by Joordens and Besner, as well as being influenced by commentaries by Masson and Borowsky (1995) and Rueckl (1995). Joordens and Besner attempted to simulate the ambiguity advantage in a fully distributed model consisting of orthographic and semantic units. Although the network was able to simulate the multiple-meaning advantage on some trials, on a substantial number of trials it was unable to settle into one of the correct meaning patterns but, rather, settled into a blend of both meaning patterns. The large proportion of blend trials suggested that the network could not reflect the accuracy of human performance (Joordens \& Besner, 1994). However, some researchers have suggested that lexical decisions may not necessarily require full settling of the semantic system. Rather, it has been argued that lexical decisions could be based on an initial burst or blend state of semantic activation prior to computation of a specific meaning (Borowsky \& Masson, 1996; Gottlob, Goldinger, Stone, \& Van Orden, 1999; Piercey \& Joordens, 2000; Rueckl, 1995). The possibility that an initial blend state of activation could be sufficient for lexical decision was confirmed in simulations reported by Borowsky and Masson. Rather than utilizing full settling of the system as a basis of lexical decision, Borowsky and Masson computed a metric known as energy, which decreases as a system moves toward a basin of attraction. Their simulations revealed an advantage for words with multiple meanings, relative to words with a single meaning, in terms of the cycles required to reach a criterion energy value defined across the semantic units. However, in a simulation of the processing of ambiguous words in neutral sentence contexts in which full settling of the semantic units was required, their results revealed an ambiguity disadvantage.

On the basis of these findings, Piercey and Joordens (2000) proposed that the processing of multiple meanings may occur in two stages. In the first, the system moves very rapidly into an initial blend state of activation. This is followed by a second stage, in which the system moves toward one of the specific meaning patterns. The lexical decision advantage is attributable to the initial, efficient stage of processing, in which the system rapidly moves into a broad pattern of activation prior to the system's moving toward one of the meaning patterns (e.g., Borowksy \& Masson, 1996; Piercey \& Joordens, 2000; Rueckl, 1995). The ambiguity disadvantage in such tasks as comprehension of text or relatedness judgments, which require deeper processing than does the lexical decision task, is assumed to be a function of the second, inefficient stage of processing. The inefficiency of the second stage is attributable to interference from competition as the system moves toward one of the meaning patterns (Piercey \& Joordens, 2000).

The hypothesized facilitation/competition mechanism described in the present paper is consistent with the model proposed by Piercey and Joordens (2000) if the assumption is made that the efficient then inefficient processing of multiple meanings is a function not only of task, but also of the nature of the meaning representation. For example, well-represented meanings (e.g., in terms of semantic neighborhood measures) may serve as attractors that are sufficiently strong that, earlier in processing, the system will begin to move toward one of the specific meaning patterns and the first, efficient stage of processing will be shortened (Joordens \& Besner, 1994). In this case, competition may arise sufficiently early in processing to affect lexical decision to some extent. However, in conditions in which the activation of the meanings is relatively weak, neither meaning may serve as an attractor that is sufficiently strong for competition to substantially affect lexical decision performance (i.e., rapid word responses can be made to ambiguous words on the basis of the initial blend of activation). The proposed extension of this model can also account for the results concerning the effects of connectivity and relatedness of meanings. Within this framework, words with related meanings would be expected to exhibit a processing advantage in lexical decision only when the first stage of processing is shortened and competition effects emerge sufficiently early in processing to influence lexical decision (e.g., with words of high connectivity).

This model can also be incorporated into the feedback framework discussed above if one holds to the assumption that the two-stage dynamics described by Piercey and Joordens (2000) can influence activation patterns at the orthographic level. During the efficient stage prior to settling at the semantic level, feedback should have a more robust influence over orthographic-level dynamics (Gottlob et al., 1999). However, in conditions in which the system moves toward one of the meaning patterns early in processing, semantic feedback activation may be weaker or inconsistent, due to competition (e.g., Kawamoto et al., 1994). However, it should be noted that the extension of this framework described here does not necessarily require the inclusion of a feedback mechanism, since simulations have shown that lexical decisions can be made reliably on the basis of semantic processing without recourse to feedback (e.g., Plaut, 1997).

A recent study by Rodd et al. (2002) provides converging evidence that the efficiency of processing of a semantically ambiguous word is a function of how the meanings are represented in memory. Rodd et al. distinguished between words with multiple meanings and those with multiple meaning senses. This distinction was based on how words are represented in a dictionary. That is, some words have multiple boldfaced entries (i.e., are ambiguous between meanings), whereas others have multiple entries within a single entry (i.e., are ambiguous between senses). Rodd et al. investigated the effect 
of these variables in both visual and auditory lexical decision. Their results revealed an advantage for words ambiguous between senses but no difference or a disadvantage for words ambiguous between meanings. Rodd et al. provided an account for these results in terms of differences in the attractor structures of words ambiguous between meanings versus those ambiguous between senses. The sense advantage arises because highly correlated patterns corresponding to multiple senses form a broad, shallow basin of attraction, whereas multiple meanings correspond to separate, steeper attractors, resulting in a processing disadvantage as the system attempts to instantiate one of the meaning patterns (Rodd et al., 2002). Somewhat similar to the account described above, however, Rodd et al. noted that the sense advantage may also be attributed partially to the task utilized (i.e., lexical decision). That is, words with multiple senses may be processed efficiently in lexical decision, since a word/nonword discrimination could be made on the basis of an initial familiarity with a word's core meaning, without the need to disambiguate between different senses. This advantage may be eliminated, however, in tasks that require computation of a specific sense. Thus, it is possible that the results reported by Rodd et al. could be conceived of in terms of the twostage framework described above (Piercey \& Joordens, 2000). That is, when meanings correspond to separate stable states, the system may tend to move toward one of the meaning patterns earlier in processing, thus being more likely to affect lexical decisions. However, words ambiguous between senses initially settle into a broad pattern of activation early in processing (Rodd et al., 2002). This initial pattern of activation is a sufficient basis for a lexical decision, and therefore, a response can be made prior to computation of a specific sense. Future research should investigate what role semantic neighborhood may play in the processing of ambiguity between multiple meanings versus senses.

There are two final points concerning our interpretation of these results that should be made. First, it should be noted that although we have interpreted these results within a distributed model, this does not preclude the possibility that they could be accounted for within a localist framework. For example, Kellas et al. (1988) proposed a localist model (i.e., a modification of the interactive activation model of McClelland \& Rumelhart, 1981), in which the recognition advantage of semantically ambiguous words was attributed to an interaction of between-level facilitation and within-level competition. Such a framework could be further modified to incorporate the relation of semantic neighborhood to ambiguity in a localist fashion (e.g., Gee, 1997). Thus, although some researchers have argued that local models may have difficulty accounting for a broad range of semantic effects (e.g., Hino et al., 2002), the present research does not speak specifically to this issue.

A second issue concerns how meaning information is best characterized as influencing lexical decision. The findings reported here have been discussed in terms of a theoretical framework in which semantic-level dynamics affect lexical decision via feedback to orthography. As was discussed above, an assumption of feedback models is that participants emphasize orthographic-level processing as the basis of word/nonword discriminations (e.g., Pexman \& Lupker, 1999). However, this should not be interpreted as implying that participants do not emphasize other levels of the system. As was noted above, a recent simulation reported by Plaut (1997) demonstrated that lexical decisions could be performed accurately on the basis of semantic processing. In this model, lexical decisions are made on the basis of a measure of familiarity defined over the semantic units (Plaut, 1997). Presumably, such variables as ambiguity and semantic neighborhood would influence the familiarity value over the semantic units during the course of processing. Thus, the present results could be accounted for within a framework in which semantic-level processing is the locus of lexical decision. Another possibility that should also be given consideration, however, is that participants may not consistently emphasize a given level in lexical decision but may alter their strategies relative to the task demands or conditions (Plaut, 1997). For example, Borowsky and Masson (1996) demonstrated that meaning-level information appears to have little influence in lexical decision when illegal consonant strings are utilized as nonword fillers. In these conditions, orthographic-level information is sufficient to make the word/nonword discrimination, and therefore, there is less opportunity for meaning-level information to have an influence. In other conditions (e.g., the use of pseudohomophone nonword fillers in a lexical decision; Van Orden \& Goldinger, 1994), however, participants may have to rely primarily on semantic information to make a lexical decision. Thus, it is possible that lexical decisions do not have a specific locus per se but are partially a function of the strategies that participants adopt in a given situation. Research should be aimed at further investigating the conditions under which participants favor different levels of analysis. The relevant point here, however, is that in conditions in which semantic information does affect lexical decision, this influence is partially a function of how meanings are represented in memory.

In conclusion, in the research reported here, we attempted to investigate further the nature of the processing of ambiguous words by examining the relationship between multiple meanings and semantic neighborhood. Undoubtedly, the full nature of the relationship between these variables is quite complex, and there are a number of issues that have yet to be explored (e.g., the relationship between semantic neighborhood and the multiplemeaning/multiple-sense distinction). However, the results discussed here suggest that a model that can account for the effects of both ambiguity and semantic neighborhood requires a mechanism such that the facilitative effect of semantic ambiguity in lexical decision can be influenced by semantic competition. The present results provide some preliminary support for such a framework. The present study also illustrates that the effect of such a mechanism in visual word recognition may be substan- 
tially influenced by the nature of how multiple meanings are represented in memory.

\section{REFERENCES}

Atchley, R. A., Burgess, C., \& Keeney, M. (1999). The effect of time course and context on the facilitation of semantic features in the cerebral hemispheres. Neuropsychology, 13, 389-403.

Azuma, T., \& VAN Orden, G. C. (1997). Why safe is better than fast: The relatedness of a word's meaning affects lexical decision times. Journal of Memory \& Language, 36, 484-504.

Balota, D. A., Ferraro, F. R, \& Connor, L. T. (1991). On the early influence of meaning in word recognition: A review of the literature. In P. J. Schwanenflugel (Ed.), The psychology of word meanings (pp. 187-222). Hillsdale, NJ: Erlbaum.

Borowsky, R., \& Masson, M. E. J. (1996). Semantic ambiguity effects in word identification. Journal of Experimental Psychology: Learning, Memory, \& Cognition, 22, 63-85.

Buchanan, L., Westbury, C., \& Burgess, C. (2001). Characterizing semantic space: Neighborhood effects in word recognition. Psychonomic Bulletin \& Review, 8, 531-544.

Clark, H. H. (1973). The language-as-fixed-effect fallacy: A critique of language statistics in psychological research. Journal of Verbal Learning \& Verbal Behavior, 15, 261-262.

Forster, K. I., \& Bednall, E. S. (1976). Terminating and exhaustive search in lexical access. Memory \& Cognition, 4, 53-61.

GEE, N. R. (1997). Implicit memory and word ambiguity. Journal of Memory \& Language, 36, 253-275.

GERNSBACHER, M. A. (1984). Resolving 20 years of inconsistent interactions between lexical familiarity and orthography, concreteness, and polysemy. Journal of Experimental Psychology: General, 113, 256-281.

Gottlob, L. R., Goldinger, S. D., Stone, G. O., \& Van Orden, G. C. (1999). Reading homographs: Orthographic, phonologic, and semantic dynamics. Journal of Experimental Psychology: Human Perception \& Performance, 25, 561-574.

Hino, Y., \& LuPKER, S. J. (1996). Effects of polysemy in lexical decision and naming: An alternative to lexical access accounts. Journal of Experimental Psychology: Human Perception \& Performance, 22, 1331-1356.

Hino, Y., Lupker, S. J., \& Pexman, P. M. (2002). Ambiguity and synonymy in lexical decision, naming, and semantic categorization tasks: Interactions between orthography, phonology, and semantics. Journal of Experimental Psychology: Learning, Memory, \& Cognition, 28, 686-713.

JASTRZEMBSKI, J. E. (1981). Multiple meanings, number of related meanings, frequency of occurrence, and the lexicon. Cognitive Psychology, 13, 278-305.

JoORDENS, S., \& BECKER, S. (1997). The long and short of semantic priming effects in lexical decision. Journal of Experimental Psychology: Learning, Memory, \& Cognition, 23, 1083-1105.

Joordens, S., \& BeSNER, D. (1994). When banking on meaning is not (yet) money in the bank: Explorations in connectionist modeling. Journal of Experimental Psychology: Learning, Memory, \& Cognition, 20, 1051-1062.

Kawamoto, A. H. (1993). Nonlinear dynamics in the resolution of lexical ambiguity: A parallel distributed processing account. Journal of Memory \& Language, 32, 474-516.

Kawamoto, A. H., Farrar, W. T., \& Kello, C. T. (1994). When two meanings are better than one: Modeling the ambiguity advantage using a recurrent distributed network. Journal of Experimental Psychology: Human Perception \& Performance, 20, 1233-1247.

Kellas, G., Ferraro, F. R, \& Simpson, G. B. (1988). Lexical ambiguity and the timecourse of attentional allocation in word recognition. Journal of Experimental Psychology: Human Perception \& Performance, 14, 601-609.

KuČera, H., \& FranCis, W. N. (1967). Computationalanalysis of presentday American English. Providence, RI: Brown University Press.

LuCAS, M. (2000). Semantic priming without association: A meta-analytic review. Psychonomic Bulletin \& Review, 7, 618-630.
Massaro, D. W., Taylor, G. A., Venezky, R. L., Jastrzembski, J. E, \& LUCAS, P. A. (1980). Letter and word perception: The role of orthographic structure and visual processing in reading. Amsterdam: North-Holland.

Masson, M. E. J. (1995). A distributed memory model of semantic priming. Journal of Experimental Psychology: Learning, Memory, \& Cognition, 21, 3-23.

Masson, M. E. J., \& Borowsky, R. (1995). Unsettling questions about semantic ambiguity in connectionist models: Comment on Joordens and Besner (1994). Journal of Experimental Psychology: Learning, Memory, \& Cognition, 21, 509-514.

McClelland, J. L., \& Rumelhart, D. E. (1981). An interactive activation model of context effects in letter perception: Pt. 1. An account of basic findings. Psychological Review, 88, 375-407.

McRae, K., De Sa, V. R. \& Seidenberg, M. S. (1997). On the nature and scope of featural representations of word meaning. Journal of Experimental Psychology: General, 126, 99-130.

Metcalf, K., Kellas, G., \& VU, H. (1999, November). Limits of contextual constraint on lexical ambiguity resolution. Paper presented at the 40th Annual Meeting of the Psychonomic Society, Los Angeles.

Millis, M. L., \& Button, S. B. (1989). The effect of polysemy on lexical decision time: Now you see it, now you don't. Memory \& Cognition, 17, 141-147.

Nelson, D. L., Bennett, D. J., Gee, N. R, \& Schreiber, T. A. (1993). Implicit memory: Effects of network size and interconnectivity on cued recall. Journal of Experimental Psychology: Learning, Memory, \& Cognition, 19, 747-764.

Nelson, D. L., McEvoy, C. L., \& Schreiber, T. A. (1999). The University of South Florida word association, rhyme, and word fragment norms [On-line document]. Available at http://www.usf.edu/Free Association.

Nelson, D. L., McEvoy, C. L., Walling, J. R. \& Wheeler, J. W., Jr. (1980). The University of South Florida homograph norms. Behavior Research Methods \& Instrumentation, 12, 16-37.

Pecher, D. (2001). Perception is a two-way junction: Feedback semantics in word recognition. Psychonomic Bulletin \& Review, 8, 545-551.

Pexman, P. M., \& Lupker, S. J. (1999). Ambiguity and visual word recognition: Can feedback explain both homophone and polysemy effects? Canadian Journal of Experimental Psychology, 53, 323-334.

Pexman, P. M., Lupker, S. J., \& Hino, Y. (2002). The impact of feedback semantics in visual word recognition: Number-of-features effects in lexical decision and naming tasks. Psychonomic Bulletin \& Review, 9, 542-549.

Piercey, C. D., \& Joordens, S. (2000). Turning an advantage into a disadvantage: Ambiguity effects in lexical decision versus reading tasks. Memory \& Cognition, 28, 657-666.

Plaut, D. C. (1997). Structure and function in the lexical system: Insights from distributed models of word reading and lexical decision. Language \& Cognitive Processes, 12, 765-805.

RaAijmakers, J. G. W., Schrijnemakers, J. M. C., \& Gremmen, F. (1999). How to deal with "the language-as-fixed-effect fallacy": Common misconceptions and alternative solutions. Journal of Memory \& Language, 41, 416-426.

RAYNer, K., \& Duffy, S. A. (1986). Lexical complexity and fixation times in reading: Effects of word frequency, verb complexity, and lexical ambiguity. Memory \& Cognition, 14, 191-201.

RodD, J., Gaskell, G., \& MARSLEn-Wilson, W. (2002). Making sense of semantic ambiguity: Semantic competition in lexical access. Journal of Memory \& Language, 46, 245-266.

Rubenstein, H., Garfield, L., \& Millikan, J. A. (1970). Homographic entries in the internal lexicon. Journal of Verbal Learning \& Verbal Behavior, 9, 487-494.

RuECKL, J. G. (1995). Ambiguity and connectionist networks: Still settling into a solution-commentary on Joordens and Besner (1994). Journal of Experimental Psychology: Learning, Memory, \& Cognition, 21, 501-508.

SCHNEIDER, W. (1988). Micro Experimental Laboratory: An integrated system for IBM PC compatibles. Behavior Research Methods, Instruments, \& Computers, 20, 206-217.

Schreiber, T. A., \& CARTER, K. (in press). The activation of preexisting associations in an episodic memory task. Memory. 
Simpson, G. B., \& Adamopoulos, A. (2001). Repeated homographs in word and sentence contexts: Multiple processing of multiple meanings. In D. S. Gorfein (Ed.), On the consequences of meaning selection: Perspectives on resolving lexical ambiguity (pp. 105-117). Washington, DC: American Psychological Association.

Simpson, G. B., \& Burgess, C. (1985). Activation and selection processes in the recognition of ambiguous words. Journal of Experimental Psychology: Human Perception \& Performance, 11, 2839.

Strain, E., Patterson, K., \& Seidenberg, M. S. (1995). Semantic effects in single-word naming. Journal of Experimental Psychology: Learning, Memory, \& Cognition, 21, 1140-1154.

Twilley, L. C., Dixon, P., TAY lor, D., \& Clark, K. (1994). University of Alberta norms of relative meaning frequency for 566 homographs. Memory \& Cognition, 22, 111-126.

VAn Orden, G. C., \& Goldinger, S. D. (1994). Interdependence of form and function in cognitive systems explains the perception of printed words. Journal of Experimental Psychology: Human Perception \& Performance, 20, 1269-1291.

YAtes, M. C., Locker, L., \& Simpson, G. B. (2001, November). Investigating the interaction of semantics and phonology in visual word recognition. Paper presented at the 42nd Annual Meeting of the Psychonomic Society, Orlando, FL.

\section{NOTES}

1. This appears to be the case for many ambiguous words. However, in the case of words that are extremely polarized in terms of meaning frequency, the associates may be reflective only of the dominant meaning. This is not surprising, since a single-response technique was utilized to capture semantic neighborhoods (Schreiber \& Carter, in press). As the results of a study reported by Millis and Button (1989) suggest, the single-response technique will most likely reflect the dominant meaning primarily.

2. Our interpretation of the present results has been based primarily on outcomes from subject analyses. Although Clark (1973) advocated the importance of inferences based on statistical treatment of materials as a random effect, in the present experiments the materials were rigorously selected on the basis of a number of control variables and, therefore, were by no means randomly selected. Raaijmakers, Schrijnemakers, and Gremmen (1999) noted that subject analyses are sufficient for rejection of the null hypothesis in designs in which materials have been balanced in terms of dimensions that are known to be correlated with the dependent variable (as opposed to designs in which materials are nested under treatment variables). Therefore, although we have included item analyses in the present results, outcomes from subject analyses have guided our interpretation of the results.

APPENDIX A

Materials Used in Experiment 1

\begin{tabular}{|c|c|c|c|}
\hline \multicolumn{2}{|c|}{ Large Semantic Set } & \multicolumn{2}{|c|}{ Small Semantic Set } \\
\hline $\begin{array}{c}\text { High } \\
\text { Connectivity }\end{array}$ & $\begin{array}{c}\text { Low } \\
\text { Connectivity }\end{array}$ & $\begin{array}{c}\text { High } \\
\text { Connectivity }\end{array}$ & $\begin{array}{c}\text { Low } \\
\text { Connectivity }\end{array}$ \\
\hline \multicolumn{4}{|c|}{ Ambiguous } \\
\hline $\begin{array}{l}\text { coast } \\
\text { axe } \\
\text { drink } \\
\text { suit } \\
\text { toy } \\
\text { yellow } \\
\text { brass } \\
\text { mate } \\
\text { busy } \\
\text { train }\end{array}$ & $\begin{array}{l}\text { roll } \\
\text { base } \\
\text { pit } \\
\text { ticket } \\
\text { grind } \\
\text { blow } \\
\text { plain } \\
\text { booth } \\
\text { tip } \\
\text { match }\end{array}$ & $\begin{array}{l}\text { pen } \\
\text { meal } \\
\text { sketch } \\
\text { ship } \\
\text { sight } \\
\text { bitter } \\
\text { odd } \\
\text { leaf } \\
\text { suds } \\
\text { stew }\end{array}$ & $\begin{array}{l}\text { racket } \\
\text { bark } \\
\text { brush } \\
\text { cap } \\
\text { calf } \\
\text { bank } \\
\text { slip } \\
\text { cloud } \\
\text { hound } \\
\text { perch }\end{array}$ \\
\hline \multicolumn{4}{|c|}{ Nonambiguous } \\
\hline $\begin{array}{l}\text { burn } \\
\text { movie } \\
\text { pie } \\
\text { vote } \\
\text { pants } \\
\text { farmer } \\
\text { pink } \\
\text { lab } \\
\text { damp } \\
\text { myth }\end{array}$ & $\begin{array}{l}\text { vanity } \\
\text { wire } \\
\text { zone } \\
\text { maid } \\
\text { rack } \\
\text { hole } \\
\text { tube } \\
\text { dragon } \\
\text { dare } \\
\text { tree }\end{array}$ & $\begin{array}{l}\text { slim } \\
\text { gem } \\
\text { pond } \\
\text { vest } \\
\text { chill } \\
\text { youth } \\
\text { cab } \\
\text { dinner } \\
\text { shout } \\
\text { huge }\end{array}$ & $\begin{array}{l}\text { alter } \\
\text { profit } \\
\text { dog } \\
\text { dune } \\
\text { lamp } \\
\text { pail } \\
\text { cone } \\
\text { link } \\
\text { itch } \\
\text { win }\end{array}$ \\
\hline
\end{tabular}


APPENDIX B

Materials Used in Experiment 2

\begin{tabular}{cll}
\hline & Lelated & Low Connectivity \\
\hline drink & & board \\
grave & & major \\
coat & chip \\
field & & switch \\
sign & & card \\
game & & rock \\
shape & & limit \\
dump & & vessel \\
ship & & dull \\
cross & & date \\
& & \\
lock & Unrelated & count \\
coach & & pound \\
band & park \\
kick & bank \\
cast & bridge \\
dive & fine \\
scale & trace \\
plane & club \\
course & match \\
seal & & calf \\
\hline
\end{tabular}

(Manuscript received June 12, 2002;

revision accepted for publication February 7, 2003.) 